\title{
Frameless linac-based stereotactic radiosurgery (SRS) for brain metastases: analysis of patient repositioning using a mask fixation system and clinical outcomes
}

\author{
Giuseppe Minniti ${ }^{1,2^{*}}$, Claudia Scaringi ${ }^{1}$, Enrico Clarke ${ }^{1}$, Maurizio Valeriani ${ }^{1}$, Mattia Osti ${ }^{1}$ and Riccardo Maurizi Enrici ${ }^{1}$
}

\begin{abstract}
Purpose: To assess the accuracy of patient repositioning and clinical outcomes of frameless stereotactic radiosurgery (SRS) for brain metastases using a stereotactic mask fixation system.

Patients and Methods: One hundred two patients treated consecutively with frameless SRS as primary treatment at University of Rome Sapienza Sant'Andrea Hospital between October 2008 and April 2010 and followed prospectively were involved in the study. A commercial stereotactic mask fixation system (BrainLab) was used for patient immobilization. A computerized tomography (CT) scan obtained immediately before SRS was used to evaluate the accuracy of patient repositioning in the mask by comparing the isocenter position to the isocenter position established in the planning CT. Deviations of isocenter coordinates in each direction and 3D displacement were calculated. Overall survival, brain control, and local control were estimated using the Kaplan-Meier method calculated from the time of SRS.
\end{abstract}

Results: The mean measured isocenter displacements were $0.12 \mathrm{~mm}(\mathrm{SD} 0.35 \mathrm{~mm}$ ) in the lateral direction, $0.2 \mathrm{~mm}$ (SD $0.4 \mathrm{~mm}$ ) in the anteroposterior, and $0.4 \mathrm{~mm}(\mathrm{SD} 0.6 \mathrm{~mm}$ ) in craniocaudal direction. The maximum displacement of 2.1 $\mathrm{mm}$ was seen in craniocaudal direction. The mean 3D displacement was $0.5 \mathrm{~mm}$ (SD $0.7 \mathrm{~mm}$ ), being maximum 2.9 $\mathrm{mm}$. The median survival was 15.5 months, and 1-year and 2-year survival rates were $58 \%$ and $24 \%$, respectively. Nine patients recurred locally after SRS, with 1-year and 2-year local control rates of $91 \%$ and $82 \%$, respectively. Stable extracranial disease $(P=0.001)$ and KPS $>70(P=0.01)$ were independent predictors of survival.

Conclusions: Frameless SRS is an effective treatment in the management of patients with brain metastases. The presented non-invasive mask-based fixation stereotactic system is associated with a high degree of patient repositioning accuracy; however, a careful evaluation is essential since occasional errors up to $3 \mathrm{~mm}$ may occur.

Keywords: stereotactic radiosurgery, positioning reproducibility, isocenter verification, brain metastases

\section{Introduction}

Stereotactic radiosurgery (SRS) has become increasingly used for treatment of patients with brain metastases. Its efficacy when used alone or in combination with whole brain radiation-therapy (WBRT) has been demonstrated in several randomized trials and multi-institutional studies [1-5].

\footnotetext{
* Correspondence: gminniti@ospedalesantandrea.it

'Department of Radiation Oncology, Sant' Andrea Hospital, University

Sapienza, Rome, Italy

Full list of author information is available at the end of the article
}

SRS has traditionally been performed using an invasive fixed head ring that establishes the stereotactic coordinates of the target and allows for an accuracy of immobilization and positioning less than $1 \mathrm{~mm}$ during image acquisition and treatment. More recently, as an alternative to the invasive patient fixation technique, different frameless stereotactic systems have been implemented. A variable positioning accuracy of 1-4 $\mathrm{mm}$ has been reported for frameless stereotactic systems [6-14], reflecting, at least in part, different methods in patient fixation, positioning, and assessment of accuracy. The 
use of small margin of safety that must be added to the target volume for errors in localization and set-up is essential in order to minimize the potential treatmentrelated complications of SRS. Volumes of normal brain receiving high dose of radiation are in fact predictive of the development of brain radionecrosis, which is reported in up to $47 \%$ of treated lesions for brain volumes larger than $10 \mathrm{cc}$ receiving a dose of $12 \mathrm{~Gy}$ [15].

Only limited data on tumor control and target localization have been provided specifically using linac-based frameless devices. In this study, we report our clinical experience in patients with brain metastases with the use of a commercially available frameless SRS system. In addition accuracy of target positioning was evaluated using repeat computed tomography $(\mathrm{CT})$ images.

\section{Patients and Methods}

One hundred two patients treated consecutively with frameless SRS as primary treatment at University of Rome Sapienza Sant'Andrea Hospital between October 2008 and April 2010 and followed prospectively were involved in the study. Patient characteristics are listed in Table 1. Sixty-four patients were treated for 1 metastasis, 24 patients for 2 metastases, and 14 patients for 3 metastases. The median age at the time of SRS was 64 years (range 26-81). The most common histologies were lung, breast, and melanomas. The most common location was parietal lobe followed by frontal and temporal lobe. According to RTOG recursive partitioning analysis (RPA) classes for brain metastases, 32 patients (31.5\%) were in RPA Class I, 58 patients (57\%) in RPA Class II, and $12(11.5 \%)$ patients in RPA Class III. Patients were examined clinically one month after SRS and then every 2 months. MRI was made every 2 months in the first year after the treatment, and then every 3 months or as appropriate according to the neurological conditions. The size of treated lesions was measured in three dimensions. Complete and partial response were defined as total radiographic disappearance of lesion or decrease in tumor volume $>50 \%$. Local progression was defined as radiographic increase in the size of metastatic lesion.

\section{SRS procedure}

After obtained informed consent, patients underwent contrast-enhanced T1-weighted magnetic resonance imaging (MRI) $(26 \mathrm{~cm}$ FOV, $512 \times 512$ pixel size, $1 \mathrm{~mm}$ slice interval) using a 1.5 Tesla MRI (Siemens Sonata, Siemens Medical Systems, Erlangen, Germany). Patient immobilization was achieved by using the commercially available BrainLab head mask fixation system. In addition, a mouth bite positioned against the upper dentition attached to the stereotactic frame was applied to prevent any head tilt movement. The characteristics of
Table 1 Summary of tumor charaterictiscs and treatment parameters of patients treated with radiosurgery

\begin{tabular}{|c|c|}
\hline & No $(\%)$ \\
\hline Number of patients & 102 \\
\hline Median age & 64 \\
\hline $\operatorname{Sex}(F / M)$ & $52 / 50$ \\
\hline \multicolumn{2}{|c|}{ No of lesions per patient } \\
\hline 1 lesion & $64(63 \%)$ \\
\hline 2 lesions & $24(23 \%)$ \\
\hline 3 lesions & $14(14 \%)$ \\
\hline \multicolumn{2}{|l|}{ Histology } \\
\hline lung & $54(53.5 \%)$ \\
\hline breast & $17(16.5 \%)$ \\
\hline melanoma & $14(13.5 \%)$ \\
\hline others & $17(16.5 \%)$ \\
\hline \multicolumn{2}{|l|}{ Tumor location } \\
\hline frontal & $31(20 \%)$ \\
\hline parietal & $37(24 \%)$ \\
\hline temporal & $30(19 \%)$ \\
\hline cerebellar & $23(15 \%)$ \\
\hline occipital & $26(17 \%)$ \\
\hline brainstem & $7(5 \%)$ \\
\hline \multicolumn{2}{|l|}{ Radiosurgical dose } \\
\hline 20 Gy & $86(56 \%)$ \\
\hline 18 Gy & $44(28 \%)$ \\
\hline $15-16$ & $24(16 \%)$ \\
\hline \multicolumn{2}{|l|}{ Tumor volume $\left(\mathrm{cm}^{3}\right)$} \\
\hline median & 1.6 \\
\hline range & $0.03-16.3$ \\
\hline \multicolumn{2}{|l|}{ Treated volume $\left(\mathrm{cm}^{3}\right)$} \\
\hline median & 2.2 \\
\hline range & $0.2-18.8$ \\
\hline
\end{tabular}

the system have been previously described [16]. Before the CT localization a localizer box was mounted to the BrainLAB mask system in order to provide a threedimensional (3D) stereotactic coordinate array for target localization. During the procedure the patient was laid on the CT couch with the system secured onto a custom-made platform. CT imaging was performed using the GE 16-slice scanner. CT (General Electric Medical System) scanning was done in spiral mode using a pitch of $0.75,512 \times 512$ pixel size, and slices in thickness and spacing of $1.2 \mathrm{~mm}$ acquired throughout the entire cranium. Tube voltage and tube potential were set at 130 $\mathrm{kV}$ and $300 \mathrm{~mA}$ to obtain high quality reconstructed slices.

The MRI and planning CT datasets were imported into the BrainLab planning system and stereotactic coordinates localization were performed by the software by identifying the location of six localizer rods on the outside surfaces of the right, left, and anterior walls of the localizer box. Localization establishes the 3D 
stereotactic coordinate system for treatment planning and delivery. The target volume was identified on the basis of the fused $\mathrm{CT}$ and magnetic resonance (MR) images. The gross tumor volume (GTV) was delineated as a contrast-enhancing tumor demonstrated on MRI scans. CTV was considered the same as GTV. The planning target volume (PTV) was generated by the geometric expansion of GTV plus $1.0 \mathrm{~mm}$. Radiosurgical dose was $20 \mathrm{~Gy}$ for metastases with a volume $\leq 4.3 \mathrm{~cm}^{3}$ (corresponding to a sphere of $2 \mathrm{~cm}$ in diameter), $18 \mathrm{~Gy}$ for metastases with a volume of $4.3-14.1 \mathrm{~cm}^{3}$, and 16 Gy for metastases with a volume $>14.1 \mathrm{~cm}^{3}$. Doses were prescribed to the $80-90 \%$ isodose line normalized to the maximum dose. All radiation doses were delivered in a single fraction with 6-10 noncoplanar dynamic arcs by using a 6-MV LINAC. Patients with multiple lesions often underwent treatment in several sessions over several days.

Immediately before treatment, all patients underwent CT verification to check the accuracy of isocenter position [16]. Firstly, the CT verification set was imported in the planning system and localized automatically by the planning software through identification of the stereotactic fiducials in the same way as for planning CT. Since this step spatially co-registers the stereotactic coordinate systems of planning $\mathrm{CT}$ and verification $\mathrm{CT}$ with the respect to the localizer box, errors in patient repositioning result in a shift of anatomical isocenter position. In the second step the planning $\mathrm{CT}$ and the $\mathrm{CT}$ verification were fused. Following fusion, anatomy was co-registered. Since all brain structures were spatially matched, any translation of isocenter position due to patient repositioning error resulted in a mismatch of the localizer rods of the localizer box. As consequence, the 3D stereotactic coordinates of isocenter in the verification CT changed accordingly. Finally, the new isocenter coordinates were recorded, and the isocenter shift between verification and planning CT calculated.

For deviations more than $1 \mathrm{~mm}$ the treatment was replanned on the basis of the new isocenter coordinates. The whole procedure including verification of isocenter and replanning lasted less than 8 minutes. During this time patients fitted with the mask were gently and slowly moved to a wheelchair and transported from CT simulation room to the treatment room, and positioned on the LINAC treatment couch. A post-treatment CT was performed in 60 patients. Differences in isocenter position calculated by planning CT and post-treatment CT fusion were assumed to serve as an indication of the stability on the patient's head within the mask during treatment (intra-fraction motion) and transportation.

Local control and survival from the date of SRS were calculated using the Kaplan-Meier. Deviations of isocenter coordinates in each direction were measured as mean \pm standard deviation (SD) for all patients. The 3D displacement determined by the square root of the sum of squares of the displacements seen in the 3 directions was calculated. Analysis of subgroups was performed using the log-rank test, and $\mathrm{p}=0.05$ was the criterion for statistical significance.

\section{Results}

\section{Accuracy of positioning}

The relocation accuracy of the isocenter determined from CT verification before the treatment is shown in Table 2. The mean measured isocenter displacements were $0.12 \mathrm{~mm}$ (SD $0.35 \mathrm{~mm}$ ) in the lateral direction, 0.2 $\mathrm{mm}(\mathrm{SD} 0.4 \mathrm{~mm})$ in the anteroposterior, and $0.4 \mathrm{~mm}$ (SD $0.6 \mathrm{~mm}$ ) in craniocaudal direction. The maximum displacement of $2.1 \mathrm{~mm}$ was seen in craniocaudal direction. The mean 3D displacement was $0.5 \mathrm{~mm}$ (SD 0.7 $\mathrm{mm}$ ), being maximum $2.9 \mathrm{~mm}$. A 3D displacement more than $1 \mathrm{~mm}$ was seen in 31 metastases (20\%), being more than $2 \mathrm{~mm}$ in 7 metastases $(4.5 \%)$, and requiring treatment replanning. There was a correlation between deviation of isocenters and the position of metastases in the brain, with the maximum 3D displacement observed for metastases located in the cerebellar and frontal lobes (cerebellar/frontal lobes versus other lobes, $\mathrm{p}=0.02$ ).

A post-treatment CT was made in 60 patients (Table 3). Patients fitted with the mask were transported in a wheelchair from the treatment room to the CT room. The mean measured isocenter displacements were 0.04 $\mathrm{mm}$ (SD $0.14 \mathrm{~mm}$ ) in the lateral direction, $0.06 \mathrm{~mm}$ (SD $0.15 \mathrm{~mm}$ ) in the anteroposterior direction, and $0.08 \mathrm{~mm}$ (SD $0.2 \mathrm{~mm}$ ) in craniocaudal direction. The mean 3D displacement was $0.09 \mathrm{~mm}$ (SD $0.28 \mathrm{~mm}$ ), with the maximum shift of $0.6 \mathrm{~mm}$.

Quality control procedures at the CT scanner, simulation room and linear accelerator were routinely performed. The accuracy of coincidence of the radiation isocenter of the treatment unit and the laser-defined room coordinate system for patient alignment (TC scanner, simulator and treatment rooms) resulted within $0.8 \mathrm{~mm}$.

\section{Outcome}

At a median clinical follow-up of 13.5 months (range 232 months) median survival and brain control were 15.5

\section{Table 2 Accuracy of isocenter relocation at CT verification}

\begin{tabular}{lccc}
\hline Direction $(\mathbf{m m})$ & Mean & SD & Range \\
\hline Cranio-caudal & 0.4 & 0.6 & $-1,2-2.1$ \\
Medio-lateral & 0.12 & 0.35 & $-0.9-1.4$ \\
Anterior-posterior & 0.2 & 0.4 & $-1,6-1.3$ \\
3D-displacement & 0.5 & 0.7 & $0.1-2.9$ \\
\hline
\end{tabular}

SD, standard deviation 
Table 3 Mean and standard deviation of isocenter displacement between $\mathrm{CT}$ verification and post-treatment CT

\begin{tabular}{lccc}
\hline Direction $(\mathbf{m m})$ & Mean & SD & Range \\
\hline Cranio-caudal & 0.08 & 0.2 & $-0.3-0.2$ \\
Medio-lateral & 0.04 & 0.14 & $-0.3-0.2$ \\
Anterior-posterior & 0.06 & 0.15 & $-0.5-0.4$ \\
3D-displacement & 0.09 & 0.28 & $0-0.6$ \\
\hline
\end{tabular}

SD, standard deviation

months and 12 months, respectively (Figure 1). The 1year and 2-year survival rates were $67 \%$ and $20 \%$, and respective brain control rates were $50 \%$ and $21 \%$. Fortythree percent of patients succumbed to their extracranial disease and 19\% died of progressive intracranial disease. Data were reported to July 2011. At this time 38\% of patients were alive. Intracranial tumor progression was observed in 60 patients. The 12-month and 24month actuarial rates of developing new brain metastases were $43 \%$ and $74 \%$, respectively. Nine patients recurred locally after SRS. The 1-year and 2-year local control rates were $91 \%$ and $82 \%$, respectively. Salvage WBRT was applied in 29 patients and further SRS in 30 patients. Thirty-seven metastases $(24 \%)$ had a complete response, 59 (38\%) had a partial response, and 49 (32\%) remained stable. A clinical neurological improvement of pre-SRS existing symptoms was recorded in 18 out of 57 patients (31\%) following SRS.

Extracranial disease $(P=0.0001)$, KPS $(P=0.001)$, number of metastases $(\mathrm{P}=0.01)$, and RPA class $(\mathrm{P}=$ 0.0001 ) were predictive factors for survival. On multivariate analysis stable extracranial disease $(P=0.001)$ and KPS $>70(\mathrm{P}=0.01)$ were associated with the most significant survival benefit. Stable extracranial disease ( $\mathrm{P}$ $=0.001), \mathrm{KPS}>70(\mathrm{P}=0.01)$, and number of metastases $(1 \mathrm{vs}>1, \mathrm{P}=0.001)$ were significant predictive factors for brain control; however, only extracranial disease

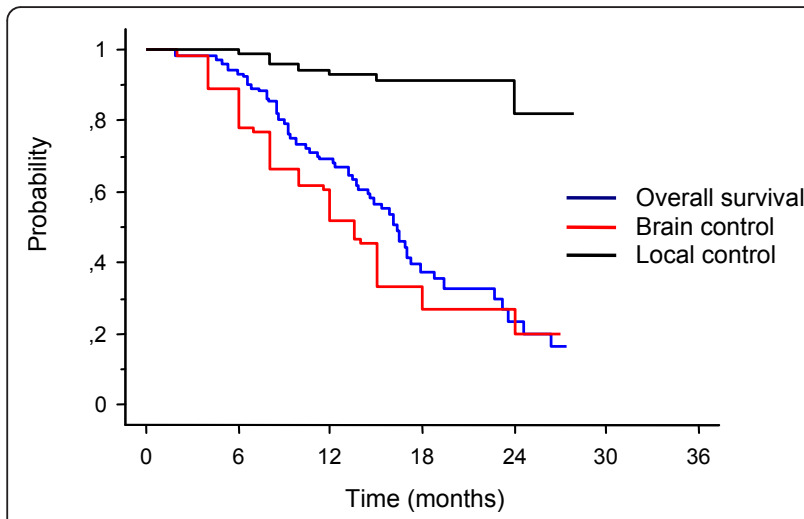

Figure 1 Kaplan-Meier analysis of overall survival, brain control, and local control.
$(P=0.006)$ and number of metastases $(P=0.005)$ were independent predictors on multivariate analysis. No significant prognostic factors were associated with local control, however there was a trend toward worse control for melanoma histology $(\mathrm{p}=0.15)$.

Brain radionecrosis, as suggested by MR imaging or confirmed by histology $(n=9)$ occurred in $39(25 \%)$ out of 154 treated lesions. Radionecrosis was symptomatic in 15 patients, being associated with severe neurological complications (RTOG Grade 3 and 4) in 7 patients.

\section{Discussion}

An essential prerequisite of a frameless stereotactic system is that patient immobilization and positioning are performed with a high degree of accuracy in order to deliver a safe therapeutic radiation dose as for invasive frame-based SRS. Different frameless stereotactic systems, including infrared camera guidance [17], dental [18-20], implanted fiducial markers [21,22], and mask fixation system [6-12] have been developed in the last two decades. In our study using a mask-based stereotactic system we have evaluated the accuracy of isocenter relocation by repeat CT scans. Mean and SD of displacements for each direction were $0.1 \mathrm{~mm}$ (SD $0.35 \mathrm{~mm}$ ) in the mediolateral direction, $0.2 \mathrm{~mm}(\mathrm{SD} 0.4 \mathrm{~mm})$ in the anteroposterior direction, and $0.4 \mathrm{~mm}(\mathrm{SD} 0.6 \mathrm{~mm}$ ) in the craniocaudal direction. The mean 3D displacement was $0.5 \mathrm{~mm}$ (SD $0.7 \mathrm{~mm}$ ), being maximum 2.9 $\mathrm{mm}$. Using a similar stereotactic mask fixation system Wong et al. [11] reported a mean and maximum 3D displacements at the isocenter evaluated by CT verification of 0.7 and $2.5 \mathrm{~mm}$, respectively. Fuss et al [13] in a series of 22 patients with 43 cranial lesions have reported a mean $3 \mathrm{D}$ target isocenter translation of 1.64 $\pm 0.84 \mathrm{~mm}$, and a maximum dislocation of $3.39 \mathrm{~mm}$, and similar results have been shown by others [7-10].

In our study repeat CT scan with a thickness of 1.2 $\mathrm{mm}$ and standard high-resolution imaging as the matrix for data acquisition was used to evaluate the accuracy of isocenter relocation. Analysis of repeated CT datasets has the advantage of high resolution imaging as compared with portal films [13], although a clear limit of our procedure is that it can not offer data on real repositioning accuracy on the treatment table. Recent development of image-guided frameless radiosurgery systems include the use of optical image guidance and X-ray to evaluate patient repositioning with an accuracy of the system similar to that reported for invasive frames [23-28]

An isocenter displacement $>1 \mathrm{~mm}$ was found in approximately $20 \%$ of treated lesions, being more than 2 $\mathrm{mm}$ in $4.5 \%$ of lesions. Although a margin from GTV to PTV expansion of $3 \mathrm{~mm}$ could compensate the inaccuracy of positioning reproducibility reported in our series, 
this will increase the volume of normal brain treated at high doses (up to 3 times for a lesion of $1.6 \mathrm{~cm}^{3}$ corresponding to our median tumor volume) and would likely be unacceptable to avoid serious treatment-related complications. Thus, in such patients the treatment was replanned according to new isocenter coordinates as calculated on the basis of CT verification. The time required for the CT verification was approximately 5 minutes. Another 7 minutes were required for image transfer, identification of the rods, fusion, recalculation of isocenter, and replanning. Our verification method allows us to use an expansion from GTV to PTV of 1 $\mathrm{mm}$ during the planning, and this may have important clinical implications. Several studies have in fact shown a significant correlation between normal brain volume receiving a dose of 12 Gy and the development of radionecrosis in patients treated with SRS for brain metastases [15,29]. In a series of 310 brain metastases treated with SRS at our institution the actuarial risk of brain radionecrosis at 1 year was up to $47 \%$ for volumes of brain larger than $10.9 \mathrm{~cm}^{3}$ treated at a dose of $12 \mathrm{~Gy}$, and similar results have been reported by others [29]. In our current clinical practice the reported procedure permits the use of strict margins for SRS while maintaining an appropriate coverage of the target, and possibly avoiding serious treatment-related complications.

The intra-fraction motion is of concern during frameless SRS. In order to evaluate the motion of the patient's head during the radiosurgical procedure, a post-treatment $\mathrm{CT}$ was performed in 60 patients. The differences in isocenter shift calculated by fusing the verification $\mathrm{CT}$ and post-treatment $\mathrm{CT}$ represent an indication of the accuracy of patient's head immobilization during either treatment or transportation from CT couch to the treatment room. The absence of significant movements during the different steps of the whole procedure confirms the excellent stability of our mask-based frameless systems and justifies its use for SRS.

Because the ultimate validity of a procedure is measured in terms of clinical results, we have examined the local control as the most sensitive clinical outcome for assessing target accuracy for brain metastases treated with frameless SRS. The tumor control of $91 \%$ at 12 months and $82 \%$ at 24 months is in the best range reported using other frameless stereotactic systems [30-32], and confirms that frameless SRS is a viable option for patients with brain metastases with an outcome similar to that observed following frame-based SRS [33-37]. Certainly, frameless SRS has several advantages compared with traditional frame-based techniques including patient comfort, greater flexibility in scheduling treatment planning and treatment procedure, possibility to treat multiple lesions in different days without the need to reapply a head frame, and the ability to use "multisession radiosurgery" to treat large lesions.

Our study has some limitations. Patient relocation evaluated by comparison of localization and verification CT scans does not include errors which are related to the treatment unit as laser alignment, machine and couch accuracy. Thus, although a margin of $1 \mathrm{~mm}$ was associated with an excellent local control and accepatable toxicity, large series and longer follow-up need to confirm the results reported in our series.

In conclusion, the results presented in this study confirm the high accuracy of patient repositioning with the use of our non-invasive mask-based fixation stereotactic system. However, a careful evaluation of the reproducibility of patient head position in the mask is essential since occasional setup errors up to $3 \mathrm{~mm}$ may occur. The promising results in terms of local control and survival support the use of linac-based frameless SRS as a common technique in the management of patients with brain metastases.

\section{Acknowledgements}

The authors wish to thanks Mr Davide Mollo, Gianluca Marrone, Matteo Luciani, and Emanuele Tosi for their excellent technical assistance and patient care.

\section{Author details}

'Department of Radiation Oncology, Sant' Andrea Hospital, University Sapienza, Rome, Italy. ${ }^{2}$ Department of Neuroscience, Neuromed Institute, Pozzilli (IS), Italy.

\section{Authors' contributions}

GM conceived of the study, participated in its design and coordination, and drafted the manuscript. CS and EC carried out the radiosurgical procedures, and participated in analysis and interpretation of data. MV and MFO participated in analysis of data and helped to draft the manuscript. RME critically reviewed/revised the article. All authors read and approved the final manuscript.

\section{Conflict of interests}

The authors declare that they have no competing interests.

Received: 7 August 2011 Accepted: 16 November 2011 Published: 16 November 2011

\section{References}

1. Pirzkall A, Debus J, Lohr F, Fuss M, Rhein B, Engenhart-Cabillic R, Wannenmacher M: Radiosurgery alone or in combination with wholebrain radiotherapy for brain metastases. J Clin Oncol 1998, 16:3563-3569.

2. Andrews DW, Scott CB, Sperduto PW, Flanders AE, Gaspar LE, Schell MC, Werner-Wasik M, Demas W, Ryu J, Bahary JP, Souhami L, Rotman M, Mehta MP, Curran WJ Jr: Whole brain radiation therapy with or without stereotactic radiosurgery boost for patients with one to three brain metastases: phase III results of the RTOG 9508 randomised trial. Lancet 2004, 363:1665-1672

3. Manon R, O'Neill A, Knisely J, Werner-Wasik M, Lazarus HM, Wagner H, Gilbert M, Mehta M, Eastern Cooperative Oncology Group: Phase II trial of radiosurgery for one to three newly diagnosed brain metastases from renal cell carcinoma, melanoma, and sarcoma: an Eastern Cooperative Oncology Group study (E 6397). J Clin Oncol 2005, 23:8870-8876.

4. Aoyama H, Shirato H, Tago M, Nakagawa K, Toyoda T, Hatano K, Kenjyo M, Oya N, Hirota S, Shioura H, Kunieda E, Inomata T, Hayakawa K, Katoh N, Kobashi G: Stereotactic radiosurgery plus whole-brain radiation therapy 
vs stereotactic radiosurgery alone for treatment of brain metastases: a randomized controlled trial. JAMA 2006, 295:2483-2491.

5. Kocher M, Soffietti R, Abacioglu U, Villà S, Fauchon F, Baumert BG, Fariselli L, Tzuk-Shina T, Kortmann RD, Carrie C, Hassel MB, Kouri M, Valeinis E, van den Berge D, Collette S, Collette L, Mueller RP: Adjuvant whole-brain radiotherapy versus observation after radiosurgery or surgical resection of one to three cerebral metastases: results of the EORTC 22952-26001 study. J Clin Oncol 2011, 29:134-141.

6. Hamilton RJ, Kuchnir FT, Pelizzari CA, Sweeney PJ, Rubin SJ: Repositioning accuracy of a noninvasive head fixation system for stereotactic radiotherapy. Med Phys 1996, 23:1909-1917.

7. Willner J, Flentje M, Bratengeier K: CT simulation in stereotactic brain radiotherapy-analysis of isocenter reproducibility with mask fixation. Radiother Oncol 1997, 45:83-88.

8. Gilbeau L, Octave-Prignot M, Loncol T, Renard L, Scalliet P, Grégoire V: Comparison of setup accuracy of three different thermoplastic masks for the treatment of brain and head and neck tumors. Radiother Oncol 2001, 58:155-162.

9. Karger CP, Jakel O, Debus J, Kuhn S, Hartmann GH: Three-dimensional accuracy and interfractional reproducibility of patient fixation and positioning using a stereotactic head mask system. Int J Radiat Oncol Biol Phys 2001, 49:1493-1504

10. Salter BJ, Fuss M, Vollmer DG, Sadeghi A, Bogaev CA, Cheek DA, Herman TS, Hevezi JM: The TALON removable head frame system for stereotactic radiosurgery/radiotherapy: measurement of the repositioning accuracy. Int J Radiat Oncol Biol Phys 2001, 51:555-562.

11. Wong W, Tung SY, Leung TW, Ho KH: CT verification of isocentre relocatability using stereotactic mask fixation system. Clin Oncol (R Coll Radiol) 2003, 15:280-287.

12. Baumert BG, Egli P, Studer S, Dehing C, Davis JB: Repositioning accuracy of fractionated stereotactic irradiation: assessment of isocentre alignment for different dental fixations by using sequential CT scanning. Radiother Oncol 2005, 74:61-66.

13. Fuss M, Salter BJ, Cheek D, Sadeghi A, Hevezi JM, Herman TS: Repositioning accuracy of a commercially available thermoplastic mask system. Radiother Oncol 2004, 71:339-345.

14. Solberg TD, Medin PM, Mullins J, Li S: Quality assurance of immobilization and target localization systems for frameless stereotactic cranial and extracranial hypofractionated radiotherapy. Int J Radiat Oncol Biol Phys 2008, 71:S131-135.

15. Minniti G, Clarke E, Lanzetta G, Osti MF, Trasimeni G, Bozzao A, Romano A Enrici RM: Stereotactic radiosurgery for brain metastases: analysis of outcome and risk of brain radionecrosis. Radiat Oncol 2011, 6:48.

16. Minniti G, Valeriani M, Clarke E, D’Arienzo M, Ciotti M, Montagnoli R Saporetti F, Enrici RM: Fractionated stereotactic radiotherapy for skull base tumors: analysis of treatment accuracy using a stereotactic mask fixation system. Radiat Oncol 2010, 13;5:1.

17. Buatti JM, Bova FJ, Friedman WA, Meeks SL, Marcus RB Jr, Mickle JP, Ellis TL, Mendenhall WM: Preliminary experience with frameless stereotactic radiotherapy. Int J Radiat Oncol Biol Phys 1998, 42:591-599.

18. Kooy HM, Dunbar SF, Tarbell NJ, Mannarino E, Ferarro N, Shusterman S, Bellerive M, Finn L, McDonough CV, Loeffler JS: Adaptation and verification of the relocatable Gill-Thomas-Cosman frame in stereotactic radiotherapy. Int J Radiat Oncol Biol Phys 1994, 30:685-691.

19. Warrington AP, Laing RW, Brada M: Quality assurance in fractionated stereotactic radiotherapy. Radiother Oncol 1994, 30:239-246.

20. Rosenthal SJ, Gall KP, Jackson M, Thornton AF Jr: A precision cranial immobilization system for conformal stereotactic fractionated radiation therapy. Int J Radiat Oncol Biol Phys 1995, 33:1239-1245.

21. Jones D, Christopherson DA, Washington JT, Hafermann MD, Rieke JW, Travaglini JJ, Vermeulen SS: A frameless method for stereotactic radiotherapy. $\mathrm{Br} J$ Radiol 1993, 66:1142-1150.

22. Kim KH, Cho MJ, Kim JS, Song CJ, Song SH, Kim SH, Myers L, Kim YE: Isocenter accuracy in frameless stereotactic radiotherapy using implanted fiducials. Int J Radiat Oncol Biol Phys 2003, 56:266-273.

23. Ryken TC, Meeks SL, Pennington EC, Hitchon P, Traynelis V, Mayr NA, Bova FJ, Friedman WA, Buatti JM: Initial clinical experience with frameless stereotactic radiosurgery: analysis of accuracy and feasibility. Int J Radiat Oncol Biol Phys 2001, 51:1152-1158.

24. Verellen D, Soete G, Linthout N, Van Acker S, De Roover P, Vinh-Hung V, Van de Steene J, Storme G: Quality assurance of a system for improved target localization and patient set-up that combines real-time infrared tracking and stereoscopic X-ray imaging. Radiother Oncol 2003, 67:129-141.

25. Keshavarzi S, Meltzer H, Ben-Haim S, Newman CB, Lawson JD, Levy ML, Murphy K: Initial clinical experience with frameless optically guided stereotactic radiosurgery/radiotherapy in pediatric patients. Childs Nerv Syst 2009, 25:837-844.

26. Ramakrishna N, Rosca F, Friesen S, Tezcanli E, Zygmanszki P, Hacker F: A clinical comparison of patient setup and intra-fraction motion using frame-based radiosurgery versus a frameless image-guided radiosurgery system for intracranial lesions. Radiother Oncol 2010, 95:109-115.

27. Verbakel WF, Lagerwaard FJ, Verduin AJ, Heukelom S, Slotman BJ, Cuijpers JP: The accuracy of frameless stereotactic intracranial radiosurgery. Radiother Oncol 2010, 97:390-394.

28. Kelly PJ, Lin YB, Yu AY, Ropper AE, Nguyen PL, Marcus KJ, Hacker FL, Weiss SE: Linear accelerator-based stereotactic radiosurgery for brainstem metastases: the Dana-Farber/Brigham and Women's Cancer Center experience. J Neurooncol 2011.

29. Blonigen BJ, Steinmetz RD, Levin L, Lamba MA, Warnick RE, Breneman JC: Irradiated volume as a predictor of brain radionecrosis after linear accelerator stereotactic radiosurgery. Int J Radiat Oncol Biol Phys 2010, 77:996-1001

30. Kamath R, Ryken TC, Meeks SL, Pennington EC, Ritchie J, Buatti JM: Initial clinical experience with frameless radiosurgery for patients with intracranial metastases. Int J Radiat Oncol Biol Phys 2005, 61:1467-1472.

31. Breneman JC, Steinmetz R, Smith A, Lamba M, Warnick RE: Frameless image-guided intracranial stereotactic radiosurgery: clinical outcomes for brain metastases. Int J Radiat Oncol Biol Phys 2009, 74:702-706.

32. Nath SK, Lawson JD, Simpson DR, Vanderspek L, Wang JZ, Alksne JF, Ciacci J, Mundt AJ, Murphy KT: Single-isocenter frameless intensitymodulated stereotactic radiosurgery for simultaneous treatment of multiple brain metastases: clinical experience. Int J Radiat Oncol Biol Phys 2010, 78:91-97.

33. Gerosa M, Nicolato A, Foroni R, Tomazzoli L, Bricolo A: Analysis of longterm outcomes and prognostic factors in patients with non-small cell lung cancer brain metastases treated by gamma knife radiosurgery. $J$ Neurosurg 2005, 102(Suppl):75-80.

34. Bhatnagar AK, Flickinger JC, Kondziolka D, Lunsford LD: Stereotactic radiosurgery for four or more intracranial metastases. Int J Radiat Oncol Biol Phys 2006, 64:898-903.

35. Gaudy-Marqueste C, Regis JM, Muracciole X, Laurans R, Richard MA, Bonerandi JJ, Grob JJ: Gamma-Knife radiosurgery in the management of melanoma patients with brain metastases: a series of 106 patients without whole-brain radiotherapy. Int J Radiat Oncol Biol Phys 2006, 65:809-816.

36. Kased N, Binder DK, McDermott MW, Nakamura JL, Huang K, Berger MS, Wara WM, Sneed PK: Gamma Knife radiosurgery for brain metastases from primary breast cancer. Int J Radiat Oncol Biol Phys 2009, 75(4):1132-1140

37. Frazier JL, Batra S, Kapor S, Vellimana A, Gandhi R, Carson KA, Shokek O, Lim M, Kleinberg L, Rigamonti D: Stereotactic radiosurgery in the management of brain metastases: an institutional retrospective analysis of survival. Int J Radiat Oncol Biol Phys 2010, 76:1486-1492.

\section{doi:10.1186/1748-717X-6-158}

Cite this article as: Minniti et al:: Frameless linac-based stereotactic radiosurgery (SRS) for brain metastases: analysis of patient repositioning using a mask fixation system and clinical outcomes. Radiation Oncology $20116: 158$ 